\title{
Characteristic of the Regional Rainy Season Onset over Vietnam: Tailoring to Agricultural Application
}

\author{
Nachiketa Acharya *(D) and Elva Bennett \\ International Research Institute for Climate and Society (IRI), The Earth Institute at Columbia University, \\ Palisades, NY 10964, USA; elva@iri.columbia.edu \\ * Correspondence: nachiketa@iri.columbia.edu
}

Citation: Acharya, N.; Bennett, E.

Characteristic of the Regional Rainy Season Onset over Vietnam: Tailoring to Agricultural Application.

Atmosphere 2021, 12, 198.

https://doi.org/10.3390/atmos12020 198

Academic Editors: Ankit Agarwal and Simone Orlandini

Received: 7 December 2020

Accepted: 28 January 2021

Published: 2 February 2021

Publisher's Note: MDPI stays neutral with regard to jurisdictional claims in published maps and institutional affiliations.

Copyright: (c) 2021 by the authors. Licensee MDPI, Basel, Switzerland. This article is an open access article distributed under the terms and conditions of the Creative Commons Attribution (CC BY) license (https:/ / creativecommons.org/licenses/by/ $4.0 /)$.

\begin{abstract}
Owing to its unique position within multiple monsoon regimes, latitudinal extent, and complex topography, Vietnam is divided into seven agroclimatic zones, each with distinct rainy season characteristics. Variation in the dominant rainfall system across zones affects the rainfall climatology, the primary water resource for regional crops. This study explores the creation of an agronomic rainy season onset based on high-resolution rainfall data for each agroclimatic zone for applications in an agricultural context. Onset information has huge practical importance for both agriculture and the economy. The spatiotemporal characteristics of zonal onset date are analyzed using integrated approaches of spatial and interannual variability, temporal changes, and estimation of predictability using teleconnection with Niño 3.4 sea surface temperature anomalies (SSTA) for 1980 to 2010. Results suggest that northern and southern zones experience regional onset dates in May, while the central zones experience rainy season onset in late August. The regional variability of rainy season onset is lower in the northern and southern zones and higher in the central zones which are latitudinally extended. The interannual variation in rainy season onset date is found to be approximately two weeks across all agroclimatic zones. The significant negative trend in rainy season onset date is found for Central Coast and South Central Coast zones, suggesting that the onset date shifted earlier for the entire period. In the decadal scale, the zonal mean onset date shifted later in the Northwest zone and earlier in the Central Highlands. Out of the seven climate zones, a significant positive correlation is only noticed in the Central Highlands and South zones between zonal mean onset date and Niño 3.4 SSTA for Dec-Jan-Feb, suggesting the potential of seasonal scale predictability of rainy season onset date with respect to preceding El Niño-Southern Oscillation (ENSO) events.
\end{abstract}

Keywords: zonal rainy season; agronomic onset definition; trend detection; ENSO-teleconnection

\section{Introduction}

In countries where rainy season rainfall is the main water resource to meet the requirements for agricultural production, reliable determination of the rainy season onset is crucial for agricultural planning. The onset date influences the time of land preparation, sowing and transplanting dates of major crops, mobilization of seed/crop, manpower, and equipment [1]. Accurate knowledge of the onset date reduces the risk of planting and sowing too late or too early [1]. Any irregularity in rainfall during this period affects the prospect of yield production because of delayed transplanting and immature growth of crop owing to water scarcity, heavy infestation by weeds, and outbreaks of diseases and insect pests [2]. Although farmers use a range of non-scientific traditional strategies and criteria (e.g., the observation of the behavior of some birds or insects and flowering of certain trees) to predict onset, these methods are unreliable, especially as global climate change alters long-term climatic patterns. Therefore, a scientific definition of the rainy season onset can aid yield increases among local farmers [3].

Defining the onset of the rainy season is an extremely complex problem and, thus, various definitions have been proposed. These definitions can be broadly classified into two 
groups: regional to large-scale methods where parameters measure large-scale atmospheric dynamics and local-scale methods using fixed precipitation thresholds selected based on the climatology of rainfall over the region of interest [4]. The local scale definition has direct application for agricultural production which depends on rainfall requirements of specific crops. Therefore, this local scale definition is often referred to as agronomic as it is based on crop-relevant local-scale daily rainfall features rather than regional-scale atmospheric circulation changes [5]. An agronomic definition can be estimated by finding the first rainy day which exceeds a particular rainfall threshold without a potential occurrence of crop-threatening dry spells thereafter to account for false onsets [5].

With spurring growth in agricultural productivity in the 1990s, the sector became a key part of Vietnam's economy, now contributing $18.4 \%$ of Vietnam's Gross Domestic Product, and employing 54\% of the working population [6]. In recent times, Vietnam became a leading global exporter of several important crops such as rice, coffee, cashew nuts, vegetables, and rubber [7]. Agricultural practices in Vietnam are crucially dependent on rainfall. The annual rainfall over Vietnam is distributed asymmetrically throughout the year, where a major proportion ( $70 \%$ of annual) of the rainfall occurs during the period from May to September/October [6]. Although most of the gross cultivated area is irrigated, irrigation itself is crucially dependent on monsoon rainfall as it largely depends on the use of surface water. Therefore, the date of onset of the rainy season is of particular importance to the agriculture sector in Vietnam. However, despite the fact that the investigation of rainy season onset dates has a huge practical importance for both agriculture and economy, targeted studies evaluating the timing of the rainy season in Vietnam have been very limited [8-10].

There are previous studies that investigate the climatology, trends, and the predictability of rainy season onset dates in southern Vietnam [8] and the Central Highlands region [9] of Vietnam. Both studies also explored prediction of rainy season onset dates based on statistical modeling using the relationship between local rainy season onset dates and large-scale atmospheric variables (pressure and moist static energy gradients, outgoing long-wave radiation, wind fields and mean sea level pressures) over certain regions. Only one study [10] discussed the climatological pattern of onset dates for all regions of Vietnam but it is limited only to the summer monsoon season while the rainy season of the Central Highlands region is mainly influenced by local rain-producing weather systems [11].

Existing studies are limited either for a particular region of the country or for only the summer monsoon season, while the climate of Vietnam substantially varies from north to south with seven climatic sub-regions which are strongly affected by multiple monsoon systems and local factors (more discussions can be found in the following sections). Thus, a more in-depth study was required to reveal an explicit understanding of the spatiotemporal characteristics of the rainy season onset of Vietnam. For the applications in an agricultural context, this study mainly focuses on the agronomic definition of onset for the primary rainy season during the period from May to September/October which has huge importance for agricultural activities, at different the agroclimatic zones of Vietnam. Nevertheless, this study is motivated to raise the following questions: How is the agronomic rainy season onset distributed over agroclimatic zones of Vietnam? How does rainy season onset vary over the spatiotemporal scale for each zone? Since the El Niño-Southern Oscillation (ENSO) has impact on the rainfall in Vietnam, is there any predictability based on the teleconnection between the onset days for each zone and with ENSO? Therefore, this paper aims to answer these issues by exploring the creation of an agronomic rainy season onset definition for all agroclimatic zones over Vietnam using recently developed high resolution Vietnam-gridded precipitation (VnGP) dataset [12] for the period 1980 to 2010. The novelty of this research lies in the fact that it is the first time that the agronomic rainy season onset for each agroclimatic zone across Vietnam is analyzed by using integrated approaches of inter-annual variability, trend analysis, and estimation of predictability teleconnection. The findings of this study offer a potential understanding of agronomic definition for the local 
stakeholders and decision-makers for agriculture as well as for the Vietnamese National Hydro-Meteorological Service (VNHMS).

The remainder of this paper is organized as follows: After a short description of the agroclimatic setting of Vietnam in Section 2, the description of the dataset is presented in Section 3. Agronomic rainy season onset definition calculation is shown in Section 4. Spatiotemporal characteristics of onset dates of each zone including interannual variability, temporal changes, together with estimation of teleconnections with El Niño-Southern Oscillation (ENSO) are presented in Section 5. The conclusions of this study follow in Section 6.

\section{The Agroclimatic Setting of Vietnam}

Vietnam, the easternmost country on the Indochina Peninsula in Southeast Asia, is bordered by China to the north, Laos and Cambodia to the west, the Gulf of Thailand to the south, and the Gulf of Tonkin and the South China Sea to the east. From the Tropic of Cancer (approximately $23.26^{\circ} \mathrm{N}$ ) to the deep tropics (approximately $8.58^{\circ} \mathrm{N}$ ), Vietnam extends $1650-\mathrm{km}$ north to south and has an extensive coastline of $3260 \mathrm{~km}$ stretching from the Gulf of Tonkin in the north to the Gulf of Thailand in the south. This long, thin, S-shaped country has a very complex topography with the mountainous North, except for the Red River valley and the coastal plain; the central highlands and coast; and the low-lying South, home to the Mekong River Delta (Figure 1a).

a)

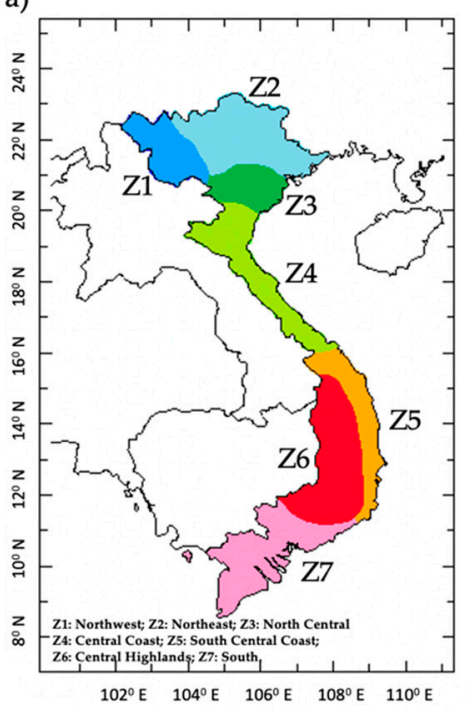

b)

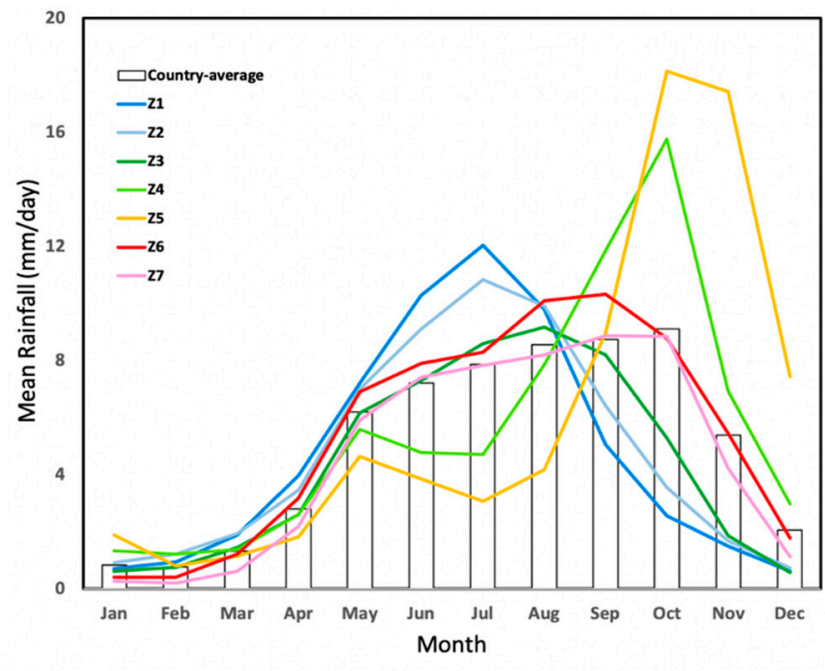

Figure 1. (a) The seven agroclimatic zones of Vietnam. (b) Monthly mean rainfall for the agroclimatic zones along with country average for 1982-2010.

The total annual rainfall is distributed unevenly throughout the year, where approximately 70 percent of the rainfall occurs during the main rainy season from May to September/October [6]. The northern region $\left(+20^{\circ} \mathrm{N}\right)$ rainy season is from May to September with the highest monthly rainfall in August. The central region $\left(11^{\circ}-20^{\circ} \mathrm{N}\right)$ rainy season has an extended bimodal rainy season from May to November with rainfall peaks in July and October. The rainy season tends to be shorter and occur later in the northern part of this elongated region. The central region has varied and unusual monsoon characteristics because of the proximity of the central highlands, eastern coast, and the effects of the adjacent mountains in Cambodia and Laos to the west. The southern region $\left(8-11^{\circ} \mathrm{N}\right)$ has a similarly extended rainy season from May to November with near constant high magnitude rainfall from June to October. Therefore, climate regimes in Vietnam are strongly affected by both monsoon systems and local factors [13]. Due to complex topography, an elongated latitudinal extent, and the influence of multiple monsoon sys- 
tems, like South Asian summer monsoon, East Asian winter monsoon, and western North Pacific monsoon, Vietnam's climate varies significantly from north to south with several sub-climate regions [13]. Vietnam is divided into seven terrestrial sub-regions with distinct climate characteristics based on the duration of the rainy season, the timing of peak rainfall, and the assessment of rainfall station data by VNHMS [10]. These zones are referred to as Northwest (denoted as Z1), Northeast (denoted as Z2), North Central (denoted as Z3), Central Coast (denoted as Z4), South Central Coast (denoted as Z5), Central Highlands (denoted as Z6), and South (denoted as Z7) (Figure 1a).

Almost $35 \%$ of the total national land area, including arable land, permanent crop land, and permanent meadow land, is used for agricultural production. Nationally, rice, coffee, tea, and pepper are the predominant crops, but the choice of the crops is specialized by agroecological zone [7]. The Northwest and Northeast zones are mountainous areas with often deficient transportation facilities, poor market access, and limited irrigation systems. The agricultural production in the northern part of Vietnam is mostly consists of industrial crops (tea and rubber) and food subsistence purposes considering that these areas are mountainous with limited irrigation systems. Cash crops (mostly coffee) are mainly produced in the Central Highlands and the South zones. Rice production is concentrated mostly in the two delta regions (Red River Delta in the North Central zone and Mekong River Delta in the South zone). Agricultural production accounts for up to 95\% of total water withdrawals in Vietnam while $49 \%$ of the total agricultural land is serviced by an irrigation scheme which is primarily designed for rice in the two deltas [7]. Irrigation is crucially dependent on monsoon rainfall because it largely depends on the use of surface water. Any aberration in rainfall during the onset time affects the prospects of a good yield as farmers make many agricultural decisions based on the local monsoon onset, including sowing dates and fertilizer timing. Therefore, it is very important to investigate the rainy season onset characteristic focusing on each sub-climate region.

\section{Dataset}

The gridded data product named Vietnam-gridded precipitation data (VnGP) is used for all the rainy season onset calculations. The dataset was built from Vietnamese National Hydro-Meteorological Service's 481 rain gauge stations. The Spheremap interpolation method, a modified Shepard's interpolation for spherical coordinates, was used to construct the gridded products from rain gauge stations. These gridded products are generated and archived by the Department of Meteorology and Climate Change, VNU University of Science, Vietnam at daily time scale with spatial resolutions of $0.1^{\circ}$ and $0.25^{\circ}$, covering the period from 1980 to 2010 . In the present study, the $0.25^{\circ}$ version for the entire 31 years (1980 to 2010) is used. The detailed procedure of the generation of VnGP has been discussed in detail by [12] and data are available at http:/ / danida.vnu.edu.vn/cpis/en/content/ gridded-precipitation-data-of-vietnam.html.

To investigate the influence of El Niño-Southern Oscillation (ENSO) over zonal rainy season onset, the sea surface temperature anomalies (SSTA) from the second version of the optimum interpolation (OI) analysis (OIv2) produced by the National Oceanic and Atmospheric Administration (NOAA) [14] is used in this study. The OIv2 has a spatial resolution of $1^{\circ}$ and a daily timescale, with monthly means from December 1981 to January 2020. The monthly mean SST anomalies from 1981 to 2010 averaged over the Niño 3.4 region of the Pacific Ocean $\left(120^{\circ} \mathrm{W}-170^{\circ} \mathrm{W}, 5^{\circ} \mathrm{S}-5^{\circ} \mathrm{N}\right)$, referred to as Nino 3.4 SSTA, are obtained from the Data Library of the International Research Institute for Climate and society at: (https:/ /iridl.ldeo.columbia.edu/SOURCES/.Indices/.nino/.NCEP_OIv2/. NINO34/index.html\#info).

\section{Methodology}

\subsection{Defining Agronomic Rainy Season Onset Based on Local-Scale Climatic Conditions}

In this work, the local rainy season onset for each agroclimatic zone is calculated using the agronomic definition proposed by [5]. As described in Section 1, a local definition 
like the one used here is of great relevance and can have numerous applications in the development of operational products in agriculture. This agronomic definition is advantageous in regions where dry and rainy seasons are well defined [4], as it is in Vietnam. This agronomic definition, originally developed using historical precipitation patterns from India, allows for the calculation of monsoon timing for any location [5]. According to this definition, rainfall onset date is defined as the first wet day within the first wet spell that is not followed by a dry spell, to avoid the false onset. A wet (dry) day is defined as being greater than (lesser or equal than) to a particular rainfall threshold depending on the local rainfall climatology. Moreover, this definition is based on five basic parameters: the amount of rainfall during the first wet spell, its duration, the duration and intensity of the post-onset dry spells, and the length of the period in which these dry spells are searched. The step by step description of this agronomic definition can be found in [5]. In the present study, the original parameters were adjusted to satisfy agronomic definition parameters based on the climatic features of Vietnam. All parameters for the initial wet spell are based on discussions with local experts at Vietnam National University (VNU) and Vietnamese National Hydro-Meteorological Service (VNHMS). In short, this method defines onset as the first wet day of the first 5-day period with an average daily rainfall equal or larger than the climatological 5-day wet spell for the season and without a 7-day dry spell (no wet days) during the following 20 days to account for false onsets.

As the focus of this paper is the rainy season, which is not limited by monsoon for the central highlands, a wet day is considered any day with at least $1 \mathrm{~mm} /$ day to account for sufficient rainfall to penetrate the soil and reach planted seeds. A requirement for five days of $5 \mathrm{~mm}$ / day rainfall is translated to $25 \mathrm{~mm}$ of rainfall in five days with at least four wet days. The reason behind choosing a higher rainfall threshold to define a wet day rather than the commonly used wet day definition $(>0.1 \mathrm{~mm} /$ day) is that a low rainfall threshold makes agronomic definition less suitable for agricultural decisions [5].

\subsection{Search Window for Onset Definition}

Finding the first wet day of the period which meets the subsequent onset date conditions (defined in Section 4.1) is necessary for the calculation of agronomic onset date in a given year; thus, determining the date of the beginning of the search the window in which to look for a day which satisfies the onset definition is a crucial step. In this study, the climatological mean monthly rainfall pattern is used to determine the beginning of the rainy season for each agroclimatic zone. As mentioned in Section 2, the predominant and intersecting monsoon systems over the different regions of Vietnam influence the onset of the rainy season across the agroclimatic zones. The East Asian Monsoon is the primary monsoonal influence on the Northern zones of Vietnam, while the South Asian monsoon dominates the southern zones. The central coastal zones and the central highlands are located between these two systems and, thus, are dominated by local rainfall patterns. The variation in the dominant rainfall system across zones affects the monthly rainfall climatology and contributes to the regional primary crop; for example, coffee in the central highlands is suited to more dispersed rainfall throughout the year with a later onset of the rainy season.

The monthly mean rainfall for each agroclimatic zone along with country average is shown in Figure 1b. It is seen that the main rainy season for northern and southern zones is during May to September, while the peak in rainfall is from July to August. For central zones it shows a decrease in rain relative to the rest of the country in the summer months and a later rainy season from August to December with a peak in rainfall in October. Further, the figure shows that the mean monthly rainfall for the whole country of Vietnam has an extended rainy season of moderate rainfall which slowly increases from May to October, and a period of low rainfall from December to April. For the 1980-2010 time period, the majority of agroclimatic zones, excluding the northwestern mountains and the central coast, experience rainy season onset after mid-April, and thus the search period begins around this time for these zones (Z2, Z3, Z6, and Z7). The Northwest (Z1) has a 
consistently earlier rainy season onset, while the Central Coast and South Central Coast zones (Z4 and Z5) are found to have a significantly delayed rainy season onset, and thus the search window shifts forward and backward, respectively, for these zones. Additionally, Summer monsoon rainfall in Vietnam has a wet-dry phase shift of 2-10 days [10] and, thus, the dry spell period for the false start parameter is seven consecutive days within the twenty-day period following the first wet day. This requirement is used to avoid false-start onsets. The search window for the rainy season onset date for each zone is 60-days to capture interannual rainy season onset date variation.

The onset date coverage is determined by the percentage of years that satisfy the agronomic onset definition criteria within the search period for each grid point for the entire 31-year study period (Figure 2). Years that do not satisfy the agronomic definition and, thus, are not included, may have had an anomalously early or late onset or unusual rainfall patterns. High onset date coverage suggests the suitability of the agronomic definition to each of the agroclimatic zones. The initial date for the search window was determined using this method of testing possible dates and assessing suitability based on coverage. The earliest date which had high coverage was deemed suitable to capture the onset of the rainy season while representing its variability of the 31-year time period. The Northwest zone (Z1) is found to have the earliest zonal rainy season onset date and the beginning day of the search window for the rainy season is set to April 15th (Figure 2a) to fully capture the interannual variability of the rainy season onset. Other beginning days of the search window were tested and found that the April 25th date (Figure 2b) captures the largest spread of onset date for the majority of zones (Z2, Z3, Z6, and Z7). Lastly, due to latitudinal extent and unique topography, the Central Coast and South Central Coast zones (Z4 and Z5) are found to have a much more variable rainy season and a later onset date. The beginning day of the search window for these zones is determined to be August 5th (Figure 2c).

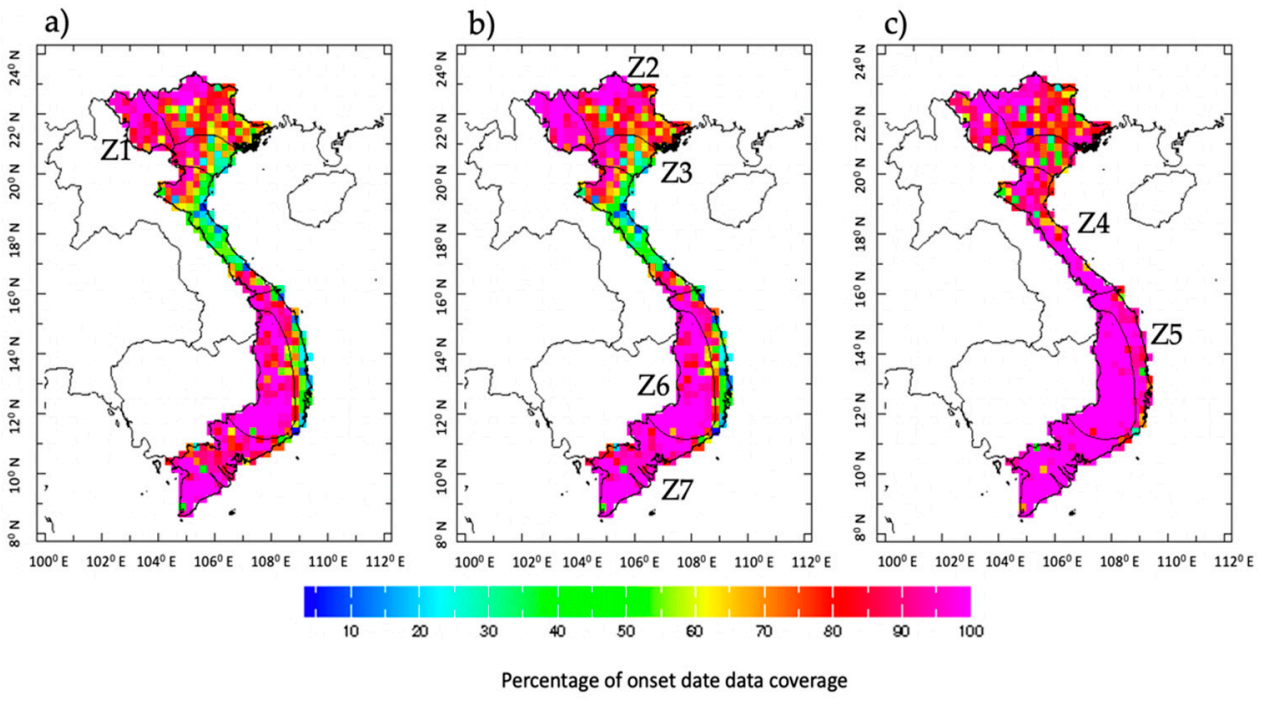

Figure 2. Onset date data coverage for search window for the rainy season set to (a) April 15th, (b) April 25th, and (c) August 5 th. Coverage is shown as a percentage, where $100 \%$ is a grid point which satisfies the agronomic definition for all years of the 1980-2010 period.

\section{Results and Discussion}

\subsection{Spatiotemporal Characteristics of Regional Onset Date}

Following the above-mentioned procedure, for each agroclimatic zone, the onset dates are estimated for each grid point independently for each year during the time period (1980-2010). The zonal mean of the onset dates for each agroclimatic zone are estimated by taking the mean of the onset dates across the time period (31 years) for each grid point within that agroclimatic zone, and, then, averaging the mean onset date across all grid 
points. It is found that the zonal mean of rainy season onset for the Northeast (Z2), North Central (Z3), and South (Z7) zones is in mid to late May (May 20th, May 21st, and May 14th, respectively). However, for the Northwest (Z1) and Central Highlands (Z6), the mean onset days are in early May (May 9th and May 11th, respectively). These onset dates are closely related to the summer monsoon system (as described in Section 5.1). Although these results are in agreement with earlier studies $[8,10]$, they are not exactly the same as a different definition is used to determine the onset dates. Lastly, the Central Coast and South Central Coast zones (Z4, Z5) have a noticeably late rainy season onset in late August (August 24th and August 29th, respectively). This is likely due to their unique topography, between the Cambodian mountain range to the west and the sea to the east, and position on the border of interacting monsoon systems.

The zonal spatial variability of the onset dates, or the variation of the mean onset date between grid points across each agroclimatic zone, is calculated to assess how coherent the onset dates are across each agroclimatic zone. The spatial variability is calculated by taking the standard deviation of all mean onset dates (mean of the onset dates across the time period for each grid point) across all grid points in a given agroclimatic zone. It is expected that the mean onset dates occur at a similar time scale across the agroclimatic zone (i.e., low zonal spatial variability of onset dates); however, it is found that the mean onset dates vary from 4 to 8 days within each zone. Moreover, spatial variability is lower in more compact zones with a single dominant monsoon regime (Z1, Z2, Z3, Z6, and Z7) at around 4-6 days and higher for latitudinally extended zones on the border of monsoon regimes ( $Z 4$ and $Z 5)$ at $7-8$ days.

The zonal interannual variability of onset date, or temporal variability, is also estimated to illustrate the year-to-year variation of onset dates in a given agroclimatic zone. This is calculated by taking the standard deviation of the onset dates across the time period for each grid point in a given zone, and, finally, averaging the standard deviation of onset date across all grid points. Interannual temporal variability of rainy season onset was found to be approximately two weeks across all agroclimatic zones. Specifically, the majority of zones (Z1, Z2, Z3, Z6, and Z7) have an interannual variability between 11 to 13 days, while the Central Coast and South Central Coast zones ( $Z 4$ and Z5) have a slightly higher interannual variability of more than 14 days. This is notable because an interannual variation of approximately two weeks presents a challenge to the prediction of rainy season at a seasonal timescale. Table 1 summarizes the mean rainy season onset day, interannual temporal variability, and spatial variability for each climatic zone.

Table 1. Mean and variability (spatial and interannual) of zonal onset date for each agroclimatic zone.

\begin{tabular}{cccc}
\hline Zone & Mean Onset Date & Spatial Variability (Days) & Interannual Variability (Days) \\
\hline 1 & May 9 & 4.5 & 13.5 \\
2 & May 20 & 6.4 & 13.4 \\
3 & May 21 & 5.4 & 13.2 \\
4 & Aug 24 & 8.1 & 14.1 \\
5 & Aug 29 & 7.1 & 14.5 \\
6 & May 11 & 5.4 & 11.5 \\
7 & May 14 & 5.2 & 13.3 \\
\hline
\end{tabular}

\subsection{Temporal Changes of Regional Onset Date}

To study the temporal changes in the onset dates for each agroclimatic zone across the time period, the Mann-Kendall (MK) test [15], a rank-based non-parametric test, is performed on the regionally averaged onset dates across all grid points (average onset dates over all grid points for each year) at the $90 \%$ statistical significance level. The MK test is widely used for trend analysis because of its robustness for non-normally distributed data and low sensitivity to an abrupt change. However, the Mann-Kendall test gives the direction (a positive or negative value of MK's test statistic indicates that the rainy season onset date is trending later or earlier respectively) but not the magnitude of the significant 
trends. Therefore, in addition, the Sen's slope estimator [16], a non-parametric test to identify the slope of the trend, is calculated to estimate the magnitude of change. The MK's test statistic and magnitude of Sen's slope for the entire study period (1980-2010) and each decade (1980s, 1990s, and 2000s, respectively) for each agroclimatic zone is shown in Figure 3. It is found that for the entire 31 years, a significant negative trend in rainy season onset date is only observed for the Central Coast and South Central Coast zones ( $\mathrm{Z} 4$ and Z5) out of all seven zones. The negative trend for both the zones represent that the onset dates shifted earlier across the entire period. The Sen's slope for the South Central Coast (Z5) has a greater magnitude than that of the Central Coast (Z4), 0.44 compared to 0.34 , which shows that the annual zonal mean rainy season onset date in the South Central Coast (Z5) shifted earlier more rapidly than in the Central Coast (Z4). Mostly there is no significant trend found for individual decades for each zone except for the Northwest and Central Highlands (Z1 and Z6) in the 1990s. For the second decade (1991-2000), a significant positive and negative trend with Sen's slope 1.647 and -2.011 are observed for the Northwest and Central Highlands (Z1 and Z6), respectively. This means that the zonal mean onset date shifted later in the northwest and earlier in the Central Highlands in this decade.

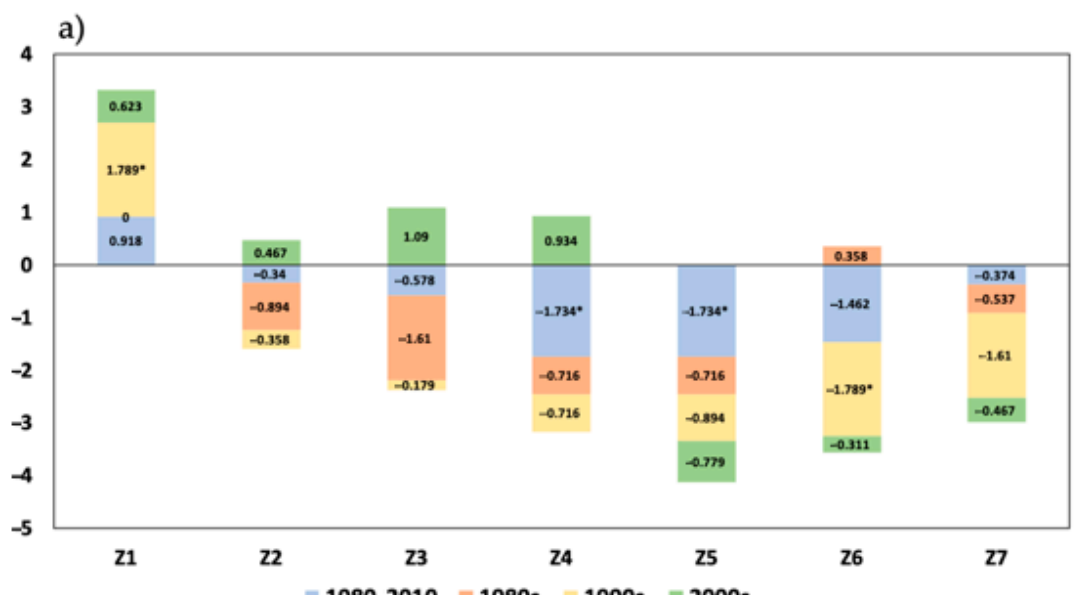

b)

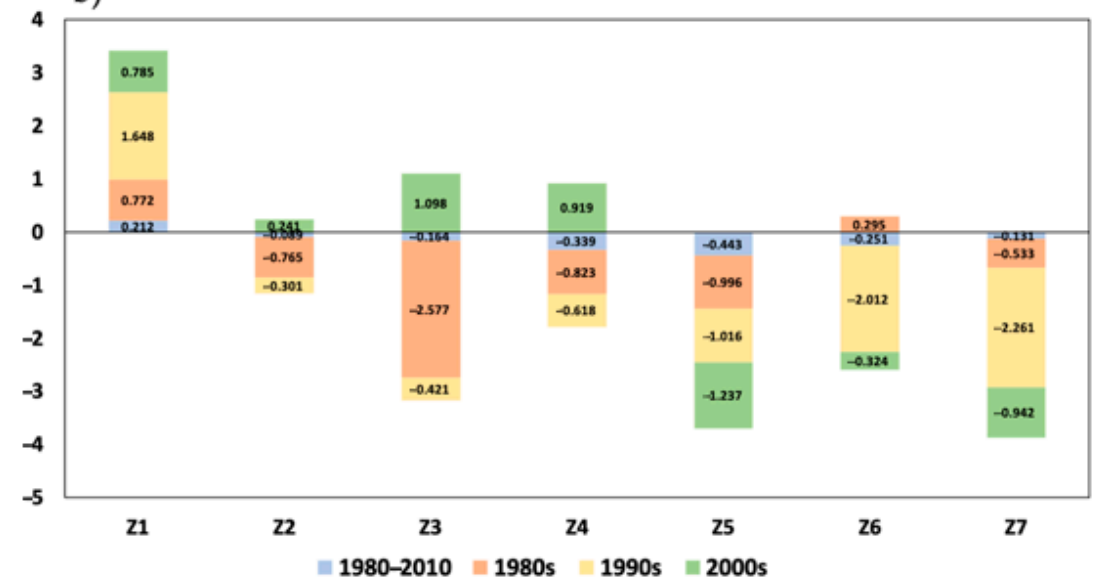

Figure 3. (a) Mann-Kendall's test statistic and (b) Sen's slope of the trend of rainy season onset for the for the entire period (1980-2010) and each decade (1980s, 1990s, and 2000s) for Northwest (Z1), Northeast (Z2), North Central (Z3), Central Coast (Z4), South Central Coast (Z5), Central Highlands (Z6), and South (Z7) agroclimatic zones. Asterisk indicates that the Mann-Kendall's test statistic values is statistically significant at $90 \%$ level.

For a visual representation, the yearly zonal mean onset dates with a linear trend line for the entire period (1980-2010) and each decade is presented for each agroclimatic zone in Figure 4. 
a)

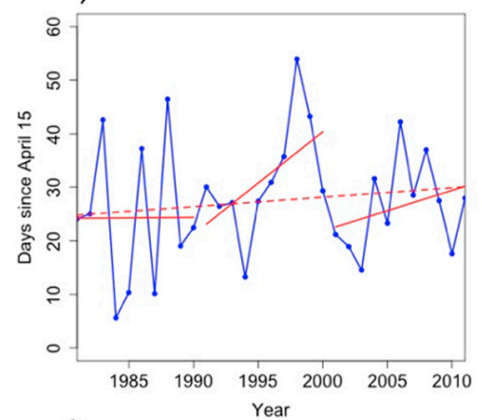

d)

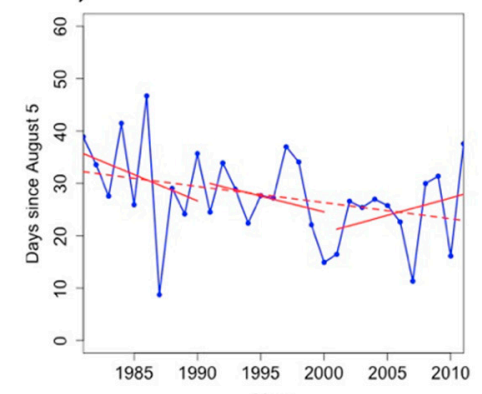

g)

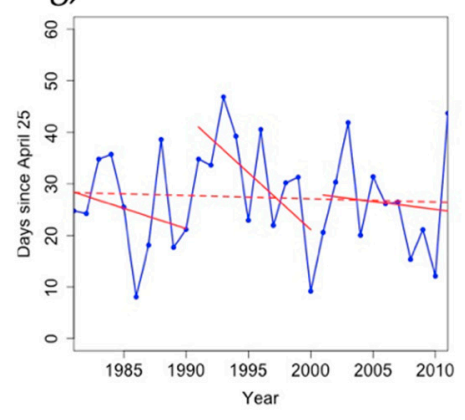

b)

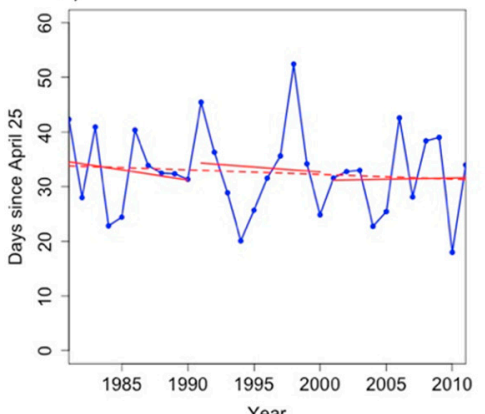

e)

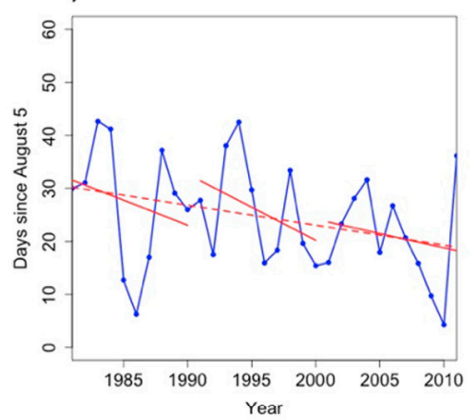

c)

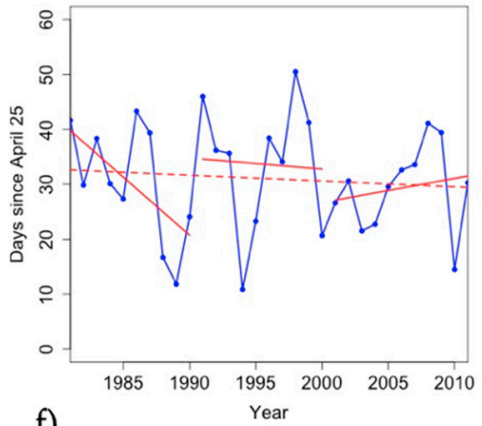

f)

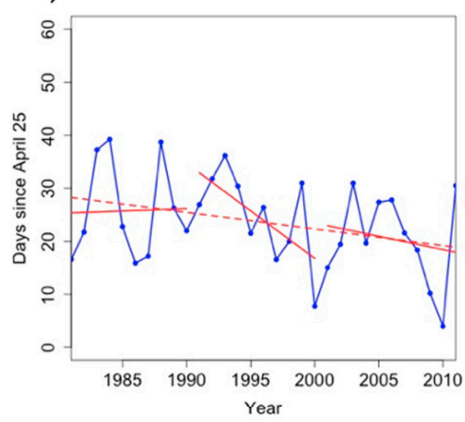

Figure 4. Yearly zonal mean onset dates (blue line) with linear trend line for the entire period (1980-2010) (dashed red line) and each decade (red line) for (a) Northwest (Z1), (b) Northeast (Z2), (c) North Central (Z3), (d) Central Coast (Z4), (e) South Central Coast (Z5), (f) Central Highlands (Z6), and (g) South (Z7) agroclimatic zones.

\subsection{Teleconnection between El Niño-Southern Oscillation (ENSO) and Regional Onset Date}

The influence of the Pacific Ocean climate drivers, namely El Niño-Southern Oscillation (ENSO), on the rainfall in Vietnam has been studied extensively $[17,18]$. Since the ENSO has an impact on rainfall in Vietnam, it may also impact the timing of the rainy season. In this section, we explore the teleconnections between the tropical Pacific SST (as represented by the Niño 3.4 SSTA) anomalies and the rainy season onset for each agroclimatic zone to investigate potential sources of seasonal predictability. The Pearson's correlation coefficient $(r)$, a measure of linear relationship, is calculated between zonal onset date for each zone and Niño 3.4 SSTA for the seasonal mean of December to February (DJF) period considering the fact that ENSO amplitude is nearing its peak around this time of the year [19]. The student's t test is performed to determine statistical significance of the correlation coefficient at the $95 \%$ level. The scatter plot between zonal onset dates and Niño 3.4 SSTA along with the Pearson's correlation coefficient is shown in Figure 5. Out of the seven agroclimatic zones, a statistically significant positive correlation is only noticed in the Central Highlands and the Southern zones $(\mathrm{Z6}, \mathrm{Z7})$ between zonal mean onset date and Niño 3.4 SSTA for DJF, while there is no correlation with ENSO found for the rest of the region. This suggests that the El Niño (La Niña) events result in a delayed (early) rainy season onset date in these two agroclimatic zones. This finding suggests the potential of seasonal prediction of rainy season onset date in these zones with respect to preceding 
ENSO events. As both the zones are significantly important for agricultural production in Vietnam (the South zone is the location of the Mekong River Delta) in terms of coffee and rice cultivation, seasonal prediction of rainy season onset would be very useful to many Vietnamese farmers in these agroclimatic zones.

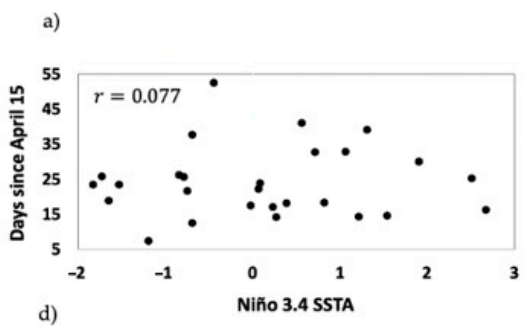

b)

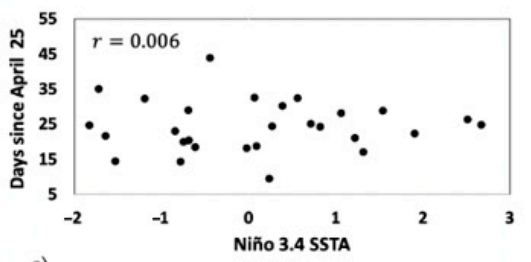

e)

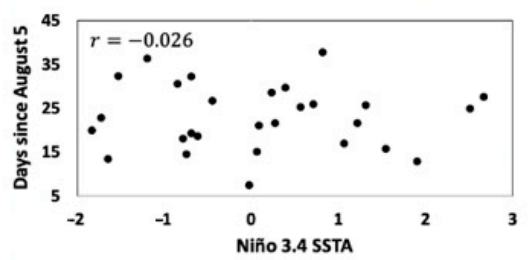

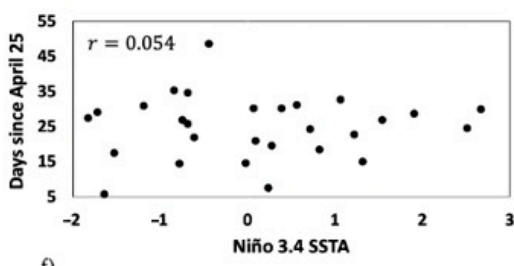

f)

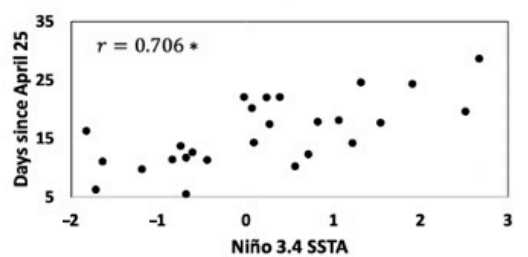

g)

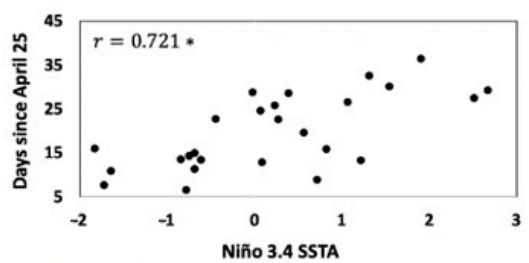

Figure 5. Scatter diagram between Niño 3.4 seas surface temperature anomaly (SSTA) (x-axis) and zonal mean onset dates (y-axis) for (a) Northwest (Z1), (b) Northeast (Z2), (c) North Central (Z3), (d) Central Coast (Z4), (e) South Central Coast (Z5), (f) Central Highlands (Z6), and (g) South (Z7) agroclimatic zones during 1980-2010. The Pearson's correlation coefficient (r) is also displayed for each zone. Asterisk indicates that the $r$ values are statistically significant at $95 \%$ level.

\section{Concluding Remarks}

The primary goal of this study is to define a rainy season onset tailored to an agricultural application over the seven primary agroclimatic zones of Vietnam and assess its spatiotemporal characteristics by using integrated approaches of spatial and interannual variability, temporal changes, and estimation of predictability using teleconnection with El Niño-Southern Oscillation (ENSO) for 1980 to 2010. The novelty of this research is that a tailored agronomic definition based on high-resolution rainfall data is used for the first time over Vietnam at a regional climate scale. The results of this study would be highly relevant to local farmers and decision-makers in Vietnam where the productivity and profitability of the agricultural sector is highly dependent on rainfall and the timing of the rainy season. In summary, the major findings of the present study are:

- Rainy season onset date varies across the agroclimatic zone. For the Northern and Southern zones, the zonal mean of rainy season onset dates is primarily in May which associated with summer monsoon system. Due to their unique topography and position on the border of interacting monsoon systems, Central Coast and South Central coast have rainy season onset in late August.

- The zonal spatial variability of onset dates, defined as the standard deviation zonal mean onset dates across all grid points in a given agroclimatic zone, varies from 4 to 8 days within each agroclimatic zone. However, the variability is lower in a single dominant monsoon regime (northern and southern zones) and higher in latitudinally extended zones on the border of monsoon regimes (Central Coast and South Central Coast). 
- The interannual variation in rainy season onset date is approximately two weeks (11 to 14 days) across all agroclimatic zones of Vietnam. This is result suggest that the prediction of rainy season onset is highly challenging work due to such high temporal variation.

- The trend analysis for the zonal onset dates of each agroclimatic zone has been analyzed by using the Mann-Kendall (MK) Test to gather with Sen's Slope Estimator for the entire 31-year period and each decade. The rainy season onset date is significantly trended earlier in the Central Coast and South Central Coast zones. For 1990s (second decade) the zonal mean onset date shifted later in the northwest and earlier in the central highlands at $90 \%$ significance level.

- $\quad$ The teleconnections between Niño 3.4 SSTA for Dec-Jan-Feb season and onset date in the Central Highlands and South zones are found (positive) to be statistically significant at $95 \%$ level. This finding suggests the potential of seasonal prediction of rainy season onset date in these zones with respect to preceding ENSO events.

Considering the fact that the seasonal prediction of rainy season onset at each climate zones would be very beneficial to the agriculture sector; the future scope of the present work includes the development of an operational forecast system using state-of-art general circulation models outputs.

Author Contributions: Conceptualization, N.A.; methodology, N.A. and E.B.; data curation, N.A. and E.B.; formal analysis, E.B.; resources, N.A.; writing-original draft preparation, N.A. and E.B.; writing-review and editing, N.A. and E.B.; visualization, N.A. and E.B.; supervision, N.A.; funding acquisition, N.A. All authors have read and agreed to the published version of the manuscript.

Funding: This research work and the APC was funded by the Columbia World Project, ACToday, Columbia University in the City of New York (https: / /iri.columbia.edu/actoday/). E.B. acknowledges the support from the Climate and Society MA program at Columbia University in the City of New York.

Institutional Review Board Statement: Not applicable.

Informed Consent Statement: Not applicable.

Data Availability Statement: Publicly available datasets were analyzed in this study. The website to access the data can be found in Section 2 of this paper.

Acknowledgments: This work is undertaken as part of the Columbia World Project, ACToday, Columbia University in the City of New York. We acknowledge the support of VNU, NOAA, and IRI personnel in creating, updating, and maintaining the dataset used in this study. We are also grateful for the effort of Rémi Cousin for making the onset calculation function in IRI's data library and for the thoughtful discussion and suggestions of scientists at the Vietnamese National Hydro-Meteorological Service (VNHMS) and the Department of Meteorology and Climate Change, VNU University of Science, Vietnam to improve the manuscript. Sincere thanks are due to the four anonymous reviewers for their constructive suggestions to enhance the quality of the manuscript.

Conflicts of Interest: The authors declare no conflict of interest.

\section{References}

1. Laux, P.; Kunstmann, H.; Bárdossy, A. Predicting the regional onset of the rainy season in West Africa. Int. J. Clim. 2008, 28, 329-342. [CrossRef]

2. Robertson, A.W.; Acharya, N.; Goddard, L.; Pattanaik, D.R.; Sahai, A.K.; Singh, K.K.; Ghosh, K.; Agarwal, A.; Buizer, J.L. Subseasonal forecasts of the 2018 Indian summer monsoon over Bihar. J. Geophys. Res. Atmos. 2019, 121, 13861-13875. [CrossRef]

3. Ati, O.F.; Stigter, C.J.; Oladipo, E.O. A comparison of methods to determine the onset of the growing season in northern Nigeria. Int. J. Clim. 2002, 22, 731-742. [CrossRef]

4. Bombardier, R.J.; Moron, V.; Goodnight, J.S. Detection, variability, and predictability of monsoon onset and withdrawal dates: A review. Int. J. Climatol 2020, 40, 641-667. [CrossRef]

5. Moron, V.; Robertson, A.W. Interannual variability of Indian summer monsoon rainfall onset date at local scale. Int. J. Clim. 2014, 34, 1050-1061. [CrossRef]

6. Tran, V.S.; Boyd, W.B.; Slavich, P.; Mai Van, T. Agriculture and climate change: Perceptions of provincial officials in Vietnam. J. Basic Appl. Sci. 2015, 11, 487-500. [CrossRef] 
7. Nguyen, T.T.N.; Roehrig, F.; Grosjean, G.; Tran, D.N.; Vu, T.M. Climate Smart Agriculture in Vietnam; CSA Country Profiles for Asia Series; International Center for Tropical Agriculture (CIAT); The Food and Agriculture Organization: Hanoi, Vietnam, 2017 ; p. 28. Available online: https:/ / hdl.handle.net/10568/96227 (accessed on 7 December 2017).

8. Thanh, P.X.; Fontaine, B.; Philippon, N. Onset of the summer monsoon over the southern Vietnam and its predictability. Theor Appl. Clim. 2010, 99, 105-113. [CrossRef]

9. Pham-Thanh, H.; van der Linden, R.; Ngo-Duc, T.; Nguyen-Dang, Q.; Fink, A.H.; Phan-Van, T. Predictability of the rainy season onset date in Central Highlands of Vietnam. Int. J. Clim. 2019, 40, 3072-3086. [CrossRef]

10. Nguyen-Le, D.; Matsumoto, J.; Ngo-Duc, T. Climatological onset date of summer monsoon in Vietnam. Int. J. Clim. 2014, 34, 3237-3250. [CrossRef]

11. Chen, T.-C.; Tsay, J.-D.; Yen, M.-C.; Matsumoto, J. Interannual variation of the late fall rainfall in Central Vietnam. J. Clim. 2012, 25, 392-413. [CrossRef]

12. Nguyen-Xuan, T.; Ngo-Duc, T.; Kamimera, H.; Trinh-Tuan, L.; Matsumoto, J.; Inoue, T.; Phan-Van, T. The Vietnam gridded precipitation (VnGP) dataset: Construction and validation. Sci. Online Lett. Atmos. SOLA 2016, 12, 291-296. [CrossRef]

13. Nguyen, D.M.; Nguyen, V.T. Definition of new summer monsoon index for Vietnam region. Vietnam. J. Sci. Technol. Eng. 2018, 60, 90-96. [CrossRef]

14. Reynolds, R.W.; Rayner, N.A.; Smith, T.M.; Stokes, D.C.; Wang, W. An improved in situ and satellite SST analysis for climate. J. Clim. 2002, 15, 1609-1625. [CrossRef]

15. Kendall, M.G. Rank Correlation Measures; Charles Griffin: London, UK, 1975; pp. 25-55.

16. Sen, P.K. Estimates of the regression coefficient based on Kendall's tau. J. Amer. Stat. Assoc. 1968, 63, 1379-1389. [CrossRef]

17. Gobin, A.; Nguyen, H.T.; Pham, V.Q.; Pham, H.T.T. Heavy rainfall patterns in Vietnam and their relation with ENSO cycles. Int. J. Clim. 2016, 36, 1686-1699. [CrossRef]

18. Duc, H.N.; Bang, H.Q.; Quang, N.X. Influence of the Pacific and Indian Ocean climate drivers on the rainfall in Vietnam. Int. J. Clim. 2018, 38, 5717-5732. [CrossRef]

19. Santoso, A.; McPhaden, M.J.; Cai, W. The defining characteristics of ENSO extremes and the Strong 2015/2016 El Niño. Rev. Geophys. 2017, 55, 1079-1129. [CrossRef] 